\title{
MATERIALES DE ÉPOCA ORIENTALIZANTE DE COÍN (MÁLAGA)
}

\section{ORIENTALISING MATERIALS FROM COÍN (MÁLAGA)}

por

\author{
JUAN ANTONIO MARTÍN RUIZ
}

\section{INTRODUCCIÓN.}

En las líneas que siguen deseamos dar a conocer dos objetos metálicos de uso personal, ambos de época orientalizante, conservados actualmente en una colección privada cuyo propietario, dándonos todo tipo de facilidades, los ha puesto a nuestra disposición para su estudio y divulgación.

Se trata de un broche de cinturón tartésico, del grupo denominado "de doble gancho", procedente del asentamiento del Cerro del Aljibe, situado en término municipal de Coín, de donde provienen, además, otros tres broches tartésicos de similares características (Martín 1997-98: 241-242), así como parte de una fíbula de doble resorte, en este caso hallada en el yacimiento de Villalba, también en dicho término municipal, y muy cercano al anterior pues sólo los separa el cauce del río Grande, donde se localiza una importante villa romana (Naranjo 1998: 60)

Resultan ser objetos que, aun siendo muy usuales en todo el Bajo Guadalquivir, escasean por contra en los registros arqueológicos de los yacimientos de Andalucía oriental en general y de Málaga en particular, hasta tal punto que en ocasiones se excluyen de cualquier trabajo sobre los mismos. Esperamos que los nuevos ejemplares que presentamos, junto a los que ya hemos dado a conocer, sirvan para acrecentar el interés de los investigadores hacia una zona que, estamos seguros, no tardará en depararnos nuevos datos sobre estos utensilios empleados en la vida cotidiana por unas comunidades que hemos dado en llamar tartésicas.

\section{EL MATERIAL ARQUEOLÓGICO.}

Pieza núm. 1 (figura 1, 1).

Pieza macho completa de un broche de cinturón de bronce, que corresponde al tipo II de E. Cuadrado y $\mathrm{M}^{\mathrm{a}} \mathrm{A}$. de Ascençao (1970: 498). Muestra un garfio cuyos extremos acaban en una curvatura que les permite el ensamblaje con la correa de cuero. Dicho garfio se acopla a la placa de sección rectangular, la cual carece de decoración, mediante dos remaches circulares. Está parcialmente cubierta por una pátina verde.

Longitud: $53 \mathrm{~mm}$., ancho: $58 \mathrm{~mm}$., grosor placa: $1 \mathrm{~mm}$., grosor garfio: $3 \mathrm{~mm}$. 
Pieza núm. 2 (figura 1, 2.).

Fragmento de una fíbula de doble resorte de bronce, perteneciente al tipo IA1 de Ruiz (1987: 496). Se conserva el puente de inserción de la aguja, así como uno de los resortes, formado por seis espirales de sección circular, y la unión de éste con la acanaladura de fijación, todo ello recubierto de una pátina de color verde

Long. puente: $20 \mathrm{~mm}$, gros. espiral: 2,5-3 mm.

\section{CONCLUSIONES.}

La publicación de estas breves notas contribuye a acrecentar el número de broches conocidos en este yacimiento, inserto en una zona, no lo olvidemos, donde se documentan muy pocos ejemplares, ya que en Málaga sólo se han publicado otros cuatro broches procedentes de El Castillón en Antequera (Bandera, Chaves 1993: 142). Aunque continúa en la misma tónica que los anteriores hallados en el cerro del Aljibe, es decir, fabricado en bronce sin decoración alguna, y dentro de un tipo ya constatado, resulta ser por el momento el de mayores dimensiones.

Por otro lado, la fíbula viene a avalar la existencia de una fase anterior a la ocupación romana en Villalba, fase hasta ahora no conocida. Del mismo modo, es otra pieza que tampoco abunda entre los artefactos publicados de este período en la provincia de Málaga, donde han aparecido en contadas ocasiones en ambientes indígenas (Cortijo de las Sombras en Frigiliana) y, sobre todo fenicios (Trayamar, Toscanos y Chorreras), aunque siempre en reducidas cantidades en relación con la necrópolis de Frigiliana, una de las más pródiga de toda Andalucía en cuanto a este tipo de hallazgos.

No deja de ser interesante comprobar cómo ambas piezas nos aluden a partes distintas de las vestimentas que portarían los habitantes indígenas de estos yacimientos, en el caso del Cerro del Aljibe vinculadas con los cinturones, y en el de Villalba con el sistema de sujeción de las vestiduras más amplias, como serían los mantos o túnicas, sin que por ahora sea posible atribuirlos exclusivamente a uno u otro sexo, aun cuando en la necrópolis de Cerrillo Blanco (Porcuna, Jaén), todos los broches hallados se asociaban tan sólo a enterramientos femeninos y la única fíbula de doble resorte fue encontrada en una tumba masculina (Torrecillas 1985: 107-108), extremo en el que creemos debería profundizarse en futuras investigaciones, sobre todo en lo concerniente a las necrópolis, a fin de disponer de un mayor volumen de información sobre la utilización que estas poblaciones dieron a tales artefactos, en particular en lo referente a un posible uso diferencial en virtud del sexo.

A este respecto cabría señalar que, aunque éste y los otros broches proceden de una zona de hábitat, como es el Cerro del Aljibe, el que dos de ellos estén completos podría hacernos pensar en la posible existencia en este punto de una o varias necrópolis.

Poco podemos decir acerca de la distribución del poblamiento en esta zona, al carecer de datos generados por proyectos sistemáticos. De cualquier forma, parece factible asegurar que el Río Grande, afluente de mayor caudal del río Guadalhorce, se nos confirma como el eje principal que conecta un buen número de yacimientos durante estos siglos, como pueden ser Cerro Chapí, Loma de Cuenca (Recio et alii 1992: 487), Cerro del Aljibe (Fernández 1986: 141), Villalba, Valenciana y Los Chozones I, enclaves en los que se han recogido cerámicas a mano adscribibles al repertorio cerámico indígena, como serían los cuencos carenados y las ollas, junto a otras confeccionadas a torno que ofrecen tipologías relacionadas con el ámbito colonial semita, caso de los trípodes, las cazuelas pintadas con bordes de sección triangular y las ánforas "de saco". 
La escasez de información nos impide valorar en su justa medida las relaciones existentes entre estos yacimientos y otros que, sin duda, deben existir en las inmediaciones. Sin embargo, resulta sugerente comprobar cómo todos ellos se distribuyen en zonas llanas o en pequeñas elevaciones siempre próximas al río, con toda probabilidad aprovechando el fértil valle circundante y conectadas visualmente, dada su cercanía, con el Cerro del Aljibe, asentamiento situado en altura y dotado de un recinto fortificado, del que por desgracia no sabemos si se erigió en este momento, pero que parece confirmarse como el de mayor importancia en toda el área.

Nos resta finalizar estas páginas sugiriendo una posible cronología para ambas piezas, considerando siempre que nos hallamos ante objetos carentes de contexto y que, por lo tanto, hemos de ser prudentes al respecto puesto que, dada la escasa dificultad que representaba su fabricación, perduraron durante varios siglos.

Creemos que situar el broche de cinturón entre las últimas décadas del siglo VIII a. C. y el siglo VI a.C. no resulta arriesgado si tenemos presentes otros hallazgos bien datados efectuados en el sur peninsular de este tipo de piezas (Castillo de Doña Blanca o Setefilla, por citar sólo algunos ejemplos), como sugerimos en otro lugar para los restantes broches descubiertos en el mismo sitio (Martín 1997-98: 243).

En cuanto a la fecha que podemos asignar al fragmento de fíbula, pensamos que no debe alejarse mucho de la propuesta para el broche, por cuanto la aparición de estos objetos en varios yacimientos andaluces (Setefilla, Cerro Macareno...), puede sernos de gran utilidad, ya que algunas de sus características nos evidencian que se trata de un ejemplar bastante antiguo, como serían el que presente seis espirales y que éstas tengan una sección circular en lugar de rectangular o romboidal (Ruiz 1987: 495). Considerar, por tanto, que fue elaborada, igualmente, entre los siglos VIII y VI a.C. parece lo más acertado.

En definitiva, la publicación de éstas y otras piezas de época orientalizante nos permite comenzar a vislumbrar la existencia de un poblamiento protohistórico desconocido hasta hace poco en Coín, zona que ofrece un indudable atractivo por cuanto su posición geográfica en la cuenca del Guadalhorce le permite conectar sin problemas con el mundo fenicio situado en la cercana línea de costa, más concretamente con el poblado de estuvo emplazado en el Cerro del Castillo de Fuengirola, sin negar otros posibles contactos a través de este río y su afluente el río Grande, y servir así de puente con las tierras situadas más al interior, con las que conecta fácilmente. 


\section{BIBLIOGRAFÍA}

CHAVES TRISTÁN, F.; BANDERA ROMERO, Mª L., (1993): “Los broches de cinturón llamados tartésicos. Nuevas aportaciones", en Homenaje a José $M^{a}$ Blázquez, vol. II: 139-147. Madrid.

CUADRADO DÍAZ, E.; ASÇENCAOEBRITO, M. A. DE(1970): "Broches de cinturón tartésicos llamados de doble gancho", XI Congreso Nacional de Arqueología: 494-514.

FERNÁNDEZ RUIZ, J. (1986): "Restos iberorromanos del Cerro del Aljibe (Coín, Málaga)”, Baetica 8: $135-141$.

MARTÍN RUIZ, J. A. (1997-98): “Broches de cinturón tartésicos procedentes del Cerro del Aljibe (Coín, Málaga)", Mainake XIX-XX: 241-245.

NARANJO NÚÑEZ, R. (1998): Historia de la ciudad de Coín. Coín, Ayuntamiento de Coín-Diputación Provincial de Málaga.

RECIO RUIZ, A.; MARTÍN CÓRDOBA, E.; RAMOS MUÑOZ, J. (1992): "Proyecto: investigaciones arqueológicas en la cuenca media del Guadalhorce. Prospección arqueológica superficial en yacimientos ibéricos de la cuenca vertiente del río Guadalhorce (Málaga)", en Investigaciones arqueológicas en Andalucía, 1985-1992. Proyectos: 481-487.

RUIZDELGADO, M. M. ${ }^{a}$ (1987): "La fíbula de doble resorte en Andalucía (I): tipos y cronología", Habis 17: 491-514.

- (1988): "La fíbula de doble resorte en Andalucía (II): aspectos mecánicos, origen y difusión”, Habis 18-19: 515-530.

TORRECILLAS GONZÁLEZ, J.F. (1985): La necrópolis de época tartésica del Cerrillo Blanco (Porcuna, Jaén). Jaén, Diputación Provincial. 


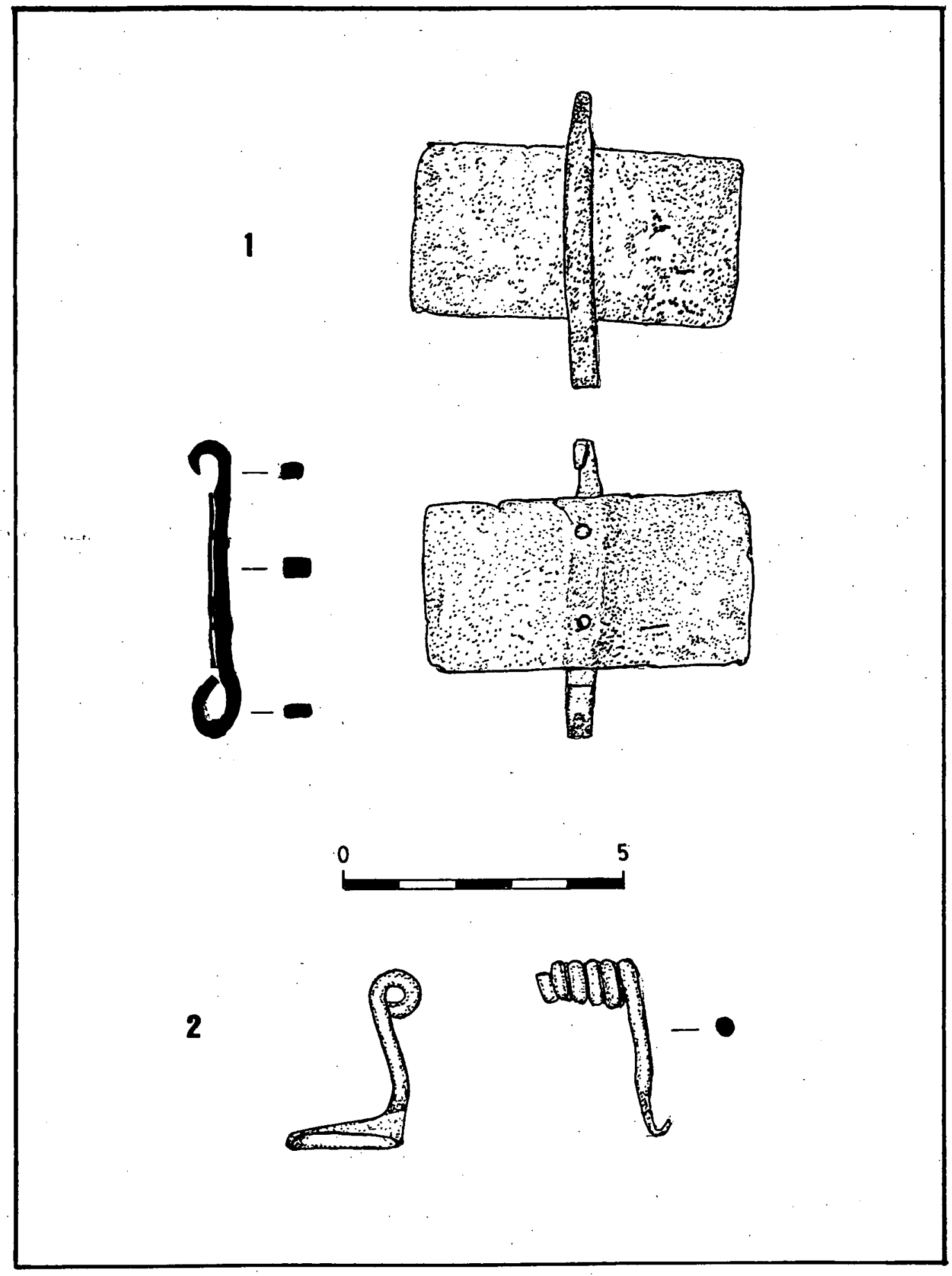

Figura 1. Broche de cinturón del Cerro del Aljibe y fíbula de doble resorte de Villalba. 